"Mircea cel Batran" Naval Academy Scientific Bulletin, Volume XIX - 2016 - Issue 2

The journal is indexed in: PROQUEST / DOAJ / Crossref / EBSCOhost / INDEX COPERNICUS / DRJI / OAJI I JOURNAL INDEX I I2OR / SCIENCE LIBRARY INDEX / Google Scholar / Academic Keys/ ROAD Open Access I Academic Resources / Scientific Indexing Services / SCIPIO / JIFACTOR

\title{
METHOD FOR OBTAINING THE CHARACTERISTICS OF WINGS
}

\author{
Beazit ALI ${ }^{1}$ \\ Anastase PRUIU ${ }^{2}$ \\ Adrian POPA ${ }^{3}$ \\ Levent $\mathrm{ALI}^{4}$
}

${ }^{1}$ Professor Ph.D. Eng.,Marine Engineering and Naval Weapons Department, "Mircea cel Batan" Naval Academy, Constanţa, Romania

${ }^{2}$ Professor Ph.D. Eng., Marine Engineering and Naval Weapons Department, "Mircea cel Batran" Naval Academy, Constanţa, Romania

${ }^{3}$ Senior Lecturer Ph.D. Eng., Marine Engineering and Naval Weapons Department, "Mircea cel Batran" Naval Academy, Constanţa, Romania

${ }^{4}$ Ph.D. attendee Eng., Bureau Veritas Romania Controle International, Romania

Abstract: This scientific work presents the way in which the small, and very small span wings can be obtained starting from the great span wings and using the two scales of the similarity theory. Basing on two scales model it can transcribe from a model at nature the coefficients $c_{x}, c_{y}$ and lengthening $\lambda$ of Gottingen - 612 profile.

Keywords: similarity theory, span, model wing, distort ratio, elongation

\section{Introduction}

In the following we will set out the coordinates (the polars) of wings of small and very small elongation, which can be obtained starting from the coordinates of the wings of big elongation, if the theory of similitude is used at two scales. In order to obtain this it is necessary to transcribe from model to nature the coefficients $c_{x}, c_{y}$ and elongation $\lambda$, according to the model at two scales of the wing.

Transcription of the coefficients $c_{x}, c_{y}$ and $c_{M}$ according to the model at two scales In the case of the rectangular wing in a plane, having string $c$ constant all along the span (in this case the wing is called aerodynamically twisted with the angle of attack variable along the span) the surface of the wing is determined by the relation:

$$
S=c \cdot l
$$

The relative elongation of the wing is:

$$
\lambda=\frac{l^{2}}{S}=\frac{l^{2}}{l \cdot c}=\frac{l}{c}
$$

Since $K_{l}=K_{z}$ and $K_{c}=K_{x}$ the scale of the elongation is:

$$
K_{\lambda}=\frac{K_{l}}{K_{c}}=\frac{K_{z}}{K_{x}}=\frac{\lambda_{n}}{\lambda_{m}}=K_{1}
$$

$\lambda_{n}=K_{1} \cdot \lambda_{m} ; K_{1}$ - distort ratio

from which results the relation of elongation transcription:

$$
\lambda_{n}=K_{1} \cdot \lambda_{m} ; \quad K_{1} \text { - distort ratio }
$$

If we write the wing's bearing force like:

$$
R_{y}=c_{y} \cdot S \cdot \frac{\rho \cdot v^{2}}{2}
$$

We have:

$$
K_{R}=K_{R_{y}}=K_{c_{y}} \cdot K_{S} \cdot K_{\rho} \cdot K_{v}^{2}=K_{c_{y}} \cdot K_{z} \cdot K_{x} \cdot K_{\rho} \cdot K_{v}^{2}
$$

The scale of the forces can also be written like:

$$
K_{R}=K_{R_{y}}=K_{1}^{2} \cdot K_{\rho} \cdot K_{v}^{2} \cdot K_{x}^{2}=K_{\rho} \cdot K_{z}^{2} \cdot K_{v}^{2}
$$

Moreover, by the equalization of the relations (6) and (7) we get:

$$
K_{c_{y}} \cdot K_{z} \cdot K_{x} \cdot K_{\rho} \cdot K_{v}^{2}=K_{\rho} \cdot K_{z}^{2} \cdot K_{v}^{2}
$$

hence resulting the scale of the unitary coefficient of the bearing force:

$$
K_{c_{y}}=\frac{c_{y_{n}}}{c_{y_{m}}}=\frac{K_{z}}{K_{x}}=K_{1}
$$

having thus:

$$
c_{y_{n}}=K_{1} \cdot c_{y_{m}}
$$

The advance resistance being:

$$
R_{X}=c_{X} \cdot S \cdot \frac{\rho v^{2}}{2}
$$

Moreover, taking into account the relation (8), because the scale of forces is dependent on their nature we can write:

$K_{R}=K_{R_{x}}=K_{c_{x}} \cdot K_{z} \cdot K_{x} \cdot K_{\rho} \cdot K_{v}^{2}=K_{\rho} \cdot K_{z}^{2} \cdot K_{v}^{2}$ 
"Mircea cel Batran" Naval Academy Scientific Bulletin, Volume XIX - 2016 - Issue 2

$$
K_{c_{X}}=\frac{c_{x_{n}}}{c_{x_{m}}}=\frac{K_{z}}{K_{X}}=K_{1}
$$

having:

$$
c_{x_{n}}=K_{1} \cdot c_{x_{m}}
$$

As it is known for a given profile the coefficients $C_{x}, C_{y}$ and $C_{M}$ are functions of the incidence angle $\alpha$, and the criteria of similitude $\mathrm{Re}, \mathrm{Fr}$, Sh and Eu; also, the movement conditions of the wing in the unlimited fluid in the vicinity of a solid or fluid surface have a great influence.

Let's examine now the scale of $C_{M}$ in condition of similitude at two scales, with small angles of attack. In this case we can write the relation:

$$
M=R_{y} \cdot e
$$

In which e represents the distance from the pressure centre of the profile to its board of attack. So, we can write:

and

$$
K_{M}=K_{R} \cdot K_{c}=K_{\rho} \cdot K_{v}^{2} \cdot K_{z}^{2} \cdot K_{x}
$$

$$
K_{M}=K_{c_{M}} \cdot K_{\rho} \cdot K_{z} \cdot K_{x} \cdot K_{v}^{2} \cdot K_{X}
$$

Equalizing (16) and (17) we get:

$$
K_{\rho} \cdot K_{v}^{2} \cdot K_{z}^{2} \cdot K_{X}=K_{c_{M}} \cdot K_{\rho} \cdot K_{z} \cdot K_{x}^{2} \cdot K_{v}^{2}
$$

From which results:

$$
K_{c_{M}}=\frac{\left(c_{M}\right)_{n}}{\left(c_{M}\right)_{m}}=\frac{K_{Z}}{K_{X}}=K_{1}
$$

or:

$$
\left(c_{M}\right)_{n}=K_{1}\left(c_{M}\right)_{m}
$$

By the help of the relations (3), (10), (14) and (20) it is possible to transcribe the nondimensional $\lambda$, $c_{y}, c_{x}$ and $c_{M}$ from the model to nature, which as seen, have in nature the values from the model multiplied by the distortion ratio $K_{1}$.

Being nondimensional, these coefficients vary to the same extent when they shift from model to nature.

We should also say that in order to obtain the nature wing's hydrodynamic coefficients we can also use the following formula: If we write the speed on the model like:

$$
v_{m}=\frac{\operatorname{Re}_{m} \cdot v_{m}}{c_{m}}
$$

And having known that between the speed of the nature wing and model wing is the following relation of similitude:

$$
v_{n}=v_{m} \cdot \frac{K_{X}}{\sqrt{K_{z}}}
$$

$$
v_{n}=\frac{\operatorname{Re}_{\mathrm{m}} \cdot v_{m}}{c_{m}} \cdot \frac{\frac{c_{n}}{c_{m}}}{\sqrt{\frac{l_{n}}{\lambda_{m} \cdot c_{m}}}}
$$

from which:

$$
v_{n}=\frac{\operatorname{Re}_{\mathrm{m}} \cdot v_{m} \cdot c_{n} \cdot \sqrt{\lambda_{m} \cdot c_{m}}}{c_{m}^{2} \sqrt{l_{n}}}
$$

or:

$$
\begin{gathered}
\frac{\sqrt{c_{m}}}{c_{m}}=\frac{v_{n} \cdot \sqrt{l_{n}}}{\operatorname{Re}_{\mathrm{m}} \cdot v_{m} \cdot c_{n}} \\
c_{m} \sqrt{c_{m}}=\frac{\operatorname{Re}_{\mathrm{m}} \cdot v_{m} \cdot c_{n} \cdot \sqrt{\lambda_{m}}}{v_{n} \cdot \sqrt{l_{n}}}
\end{gathered}
$$

obtaining in this way the relation of determination of the model's string's length $C_{m}$.

$$
c_{m}=\sqrt[3]{\left(\frac{\mathrm{Re}_{\mathrm{m}} \cdot v_{m} \cdot c_{n} \cdot \sqrt{\lambda_{m}}}{v_{n} \cdot \sqrt{l_{n}}}\right)^{2}}
$$

Using the definition relation of the relative elongation we can determine the span of the model wing:

$$
l_{m}=\lambda_{m} \cdot c_{m}
$$

We calculate the scale of the string $K_{c}$ and the scale of the span $K_{l}$ :

$$
\begin{gathered}
K_{c}=K_{X}=\frac{c_{n}}{c_{m}} \\
K_{l}=K_{z}=\frac{l_{n}}{l_{m}}
\end{gathered}
$$

We determine the distortion ratio $K_{1}$

$$
K_{1}=\frac{K_{l}}{K_{c}}=\frac{K_{Z}}{K_{X}}
$$

We state the scales of density, speed, and force.

$$
\begin{aligned}
& K_{\rho}=\frac{\rho_{n}}{\rho_{m}} \\
& K_{v}=\frac{K_{x}}{\sqrt{K_{z}}}=\frac{v_{n}}{v_{m}} \\
& K_{R}=K_{\rho} \cdot K_{x}^{2} \cdot K_{z}=\frac{R_{y_{n}}}{R_{y_{m}}}=\frac{R_{x_{n}}}{R_{x_{m}}}
\end{aligned}
$$

Both the model and the real wing are rectangular in plan,and we can determine, with the known data the areas of the surfaces:

we get: 
"Mircea cel Batran" Naval Academy Scientific Bulletin, Volume XIX - 2016 - Issue 2

The journal is indexed in: PROQUEST / DOAJ / Crossref / EBSCOhost / INDEX COPERNICUS / DRJI / OAJI I JOURNAL INDEX I I2OR / SCIENCE LIBRARY INDEX / Google Scholar / Academic Keys/ ROAD Open Access I Academic Resources / Scientific Indexing Services / SCIPIO / JIFACTOR

$$
\begin{aligned}
& S_{m}=l_{m} \cdot c_{m} \\
& S_{n}=l_{n} \cdot c_{n}
\end{aligned}
$$

According to the law of the model we calculate the speed of the nature (real) wing:

$$
v_{n}=v_{m} \cdot K_{v}=v_{m} \cdot \frac{K_{X}}{\sqrt{K_{z}}}
$$

With the known data we can further determine the bearing force of the model wing:

$$
R_{y_{m}}=c_{y_{m}} \cdot S_{m} \cdot \frac{\rho_{m} \cdot v_{m}^{2}}{2}
$$

Using the law of model or the relation (7), we will calculate the bearing force of the real wing:

$$
R_{y_{n}}=K_{R} \cdot R_{y_{m}}=K_{x}^{2} \cdot K_{z} \cdot K_{\rho} \cdot R_{y_{m}}
$$

From which the coefficient of the real wing bearing force:

$$
c_{y_{n}}=\frac{R_{y_{n}}}{S_{n} \cdot \frac{\rho_{n} \cdot v_{n}^{2}}{2}}
$$

We calculate the advance resistance of the model wing:

$$
R_{x_{m}}=c_{x_{m}} \cdot S_{m} \cdot \frac{\rho_{m} \cdot v_{m}^{2}}{2}
$$

and on the basis of the law of model we get the advance resistance of the real wing:

$$
R_{x_{n}}=K_{R} \cdot R_{x_{m}}=K_{\rho} \cdot K_{X}^{2} \cdot K_{z} \cdot R_{X_{m}}
$$

From which the coefficient of advance resistance of the real wing is deduced:

$$
c_{x_{n}}=\frac{R_{x_{n}}}{S_{n} \cdot \frac{\rho_{n} \cdot v_{n}^{2}}{2}}
$$

In conclusion, taking into account what we have mentioned before, we can say that the values of the coefficients $c_{y_{n}}$ and $c_{x_{n}}$ of the real nature wing do not depend on the dimensions of the model wing; they depend only on the relative elongation of the wing, and for every single elongation of the wing only one polar is established.

It is true that if we extend the relations (10) and (14) we get:

$$
c_{y_{n}}=c_{y_{m}} \cdot \frac{K_{z}}{K_{X}}=c_{y_{m}} \cdot \frac{\frac{l_{n}}{l_{m}}}{\frac{c_{n}}{c_{m}}}=c_{y_{m}} \cdot \frac{\lambda_{n}}{\lambda_{m}}
$$

$$
c_{X_{n}}=c_{X_{m}} \cdot \frac{K_{z}}{K_{X}}=c_{X_{m}} \cdot \frac{\frac{l_{n}}{l_{m}}}{\frac{c_{n}}{c_{m}}}=c_{X_{m}} \cdot \frac{\lambda_{n}}{\lambda_{m}}
$$

This is to confirm once more that within the relations between coefficients the dimensions of model wing do not interfere.

Tracing the Gottingen - 612 profile's polar with relative elongation $\lambda=3$, knowing the corresponding profile is polar corresponding to the relative elongation $\lambda=5$

The string's length $c_{n}=0,3 \mathrm{~m}$ and the ship's speed $v_{n}=25 \mathrm{~m} / \mathrm{s}$ is considered for the nature wing. We also stress that the initial polar was drawn in the aerodynamic tunnel, a small span wing under observation will function in water.

Cinematic viscosity values of the two fluids are: $v_{a e r}=0,0000143 \frac{\mathrm{m}^{2}}{\mathrm{~s}} v_{a p a}=1,191 \cdot 10^{-6} \frac{\mathrm{m}^{2}}{\mathrm{~s}}$

Thus, for the $c_{n}=0,3 \mathrm{~m}, v_{n}=25 \frac{\mathrm{m}}{\mathrm{s}}$

and $v_{\text {apa }}=1,191 \cdot 10^{-6} \frac{\mathrm{m}^{2}}{\mathrm{~s}}$ there results:

$\operatorname{Re}_{n}=\frac{v_{n} \cdot c_{n}}{v_{\text {apa }}}=\frac{25 \cdot 0,3}{1,191 \cdot 10^{-6}}=6,27 \cdot 10^{6}$

$\mathrm{Re}=6300000$

The Gottingen - 612 profile is characterized by $\lambda_{m}=5$ and $\operatorname{Re}=420000$

The following data are to be found in the specialty literature (see Table 1)

Table no. 1

\begin{tabular}{|l|l|l|}
\hline$\alpha$ & $c_{y_{m}}$ & $c_{x_{m}}$ \\
\hline$-10,4$ & $-0,340$ & 0,0796 \\
\hline$-8,9$ & $-0,250$ & 0,0216 \\
\hline$-6,0$ & $-0,056$ & 0,0096 \\
\hline$-3,0$ & 0,141 & 0,0109 \\
\hline$-0,1$ & 0,322 & 0,0159 \\
\hline 2,8 & 0,526 & 0,0261 \\
\hline 5,8 & 0,723 & 0,0437 \\
\hline 8,7 & 0,900 & 0,067 \\
\hline 11,6 & 1,044 & 0,0941 \\
\hline 14,6 & 1,073 & 0,135 \\
\hline 17,7 & 0,952 & 0,260 \\
\hline
\end{tabular}

The distortion ratios for the three elongations

$$
\begin{gathered}
\lambda_{n 1}=3 ; \lambda_{n 2}=2 \text { and } \lambda_{n 3}=1 \text { will be: } \\
K_{1}^{\prime}=\frac{\lambda_{n_{1}}}{\lambda_{m}}=\frac{3}{5}=0,6
\end{gathered}
$$


"Mircea cel Batran" Naval Academy Scientific Bulletin, Volume XIX - 2016 - Issue 2

The journal is indexed in: PROQUEST / DOAJ / Crossref / EBSCOhost / INDEX COPERNICUS / DRJI / OAJI I JOURNAL INDEX / I2OR / SCIENCE LIBRARY INDEX / Google Scholar / Academic Keys/ ROAD Open Access I Academic Resources / Scientific Indexing Services / SCIPIO / JIFACTOR

$$
\begin{aligned}
K^{\prime \prime} & =\frac{\lambda_{n_{2}}}{\lambda_{m}}=\frac{2}{5}=0,4 \\
K^{\prime \prime \prime} & =\frac{\lambda_{n_{3}}}{\lambda_{m}}=\frac{1}{5}=0,2
\end{aligned}
$$

Using the equations obtained through the theory of similitude (10) and (14) we can draw up the table 2 for the nature wing with elongation $\lambda_{n 1}=3$ :

$$
\lambda_{n_{1}}=3 ; K_{1}{ }^{\prime}=0,6 ; \operatorname{Re}_{n}=6300000
$$

\section{CONCLUSIONS}

Table no. 2

\begin{tabular}{|l|l|l|}
\hline$\alpha$ & $c_{y_{m}}$ & $c_{x_{m}}$ \\
\hline$-10,4$ & $-0,204$ & 0,0477 \\
\hline$-8,9$ & $-0,15$ & 0,0129 \\
\hline$-6,0$ & $-0,033$ & 0,00576 \\
\hline$-3,0$ & 0,091 & 0,0065 \\
\hline$-0,1$ & 0,1932 & 0,0095 \\
\hline 2,8 & 0,3156 & 0,0156 \\
\hline 5,8 & 0,434 & 0,0262 \\
\hline 8,7 & 0,54 & 0,0402 \\
\hline 11,6 & 0,626 & 0,0564 \\
\hline 14,6 & 0,644 & 0,081 \\
\hline 17,7 & 0,5712 & 0,156 \\
\hline
\end{tabular}

Going on in the same manner, that is starting from the polars of big span wings and using the theory of similitude at two scales, the polars of other profiles ( of small and very small span), which were analysed, can be built; for example: Gottingen - 439, Gottingen - 480, NACA - 4409, Clark Y, RAF - 32, Gottingen - 565, Gottingen - 670, Gottingen - 682, Gottingen - 507, and NACA - 6412, (for $\lambda=3, \lambda=2$ and $\lambda=1$ )

\section{BIBLIOGRAPHY}

[1].Niestoj W, Profile pentru aeromodele, Varşovia, 1976.

[2].Vasilescu, AL. A., Analiză dimensională şi teoria similitudinii, Editura Academiei, Bucureşti, 1969.

[3].Vasilescu, AL. A., Similitudinea sistemelor elastice, Editura Academiei, Bucureşti, 1969.

[4].Carafoli, E, Constantinescu, V. N., Dinamica fluidelor incompresibile, Editura Academiei, Bucureşti, 1981 ,

[5].Beazit Ali, Stabilirea punţii de legătură între teoria aripii de mică anvergură şi teoria aripii de mare anvergură pe fondul teoriei similitudinii la două scări, Referat de doctorat, Universitatea " Dunărea de Jos" Galaţi, 1995.

[6].Beazit Ali, Obţinerea polarelor aripilor de mică anvergură plecând de la polarele aripilor de mare anvergură, folosind teoria similitudinii la două scări, Buletinul,,Tehmar”, Constanţa, 1996.

[7].Beazit Ali, Traian Florea, Study on the upward small span profile based on the two scale similarity theory, The XII-th National Conference on Thermotechnics with International Participation, Naval Academy " Mircea cel Bătrân", Constanta, 2002. 